\title{
Standpunkt
}

\section{Allen wohl und keinem wehe}

\author{
Die „Versöhnung“ von ökonomischer Entwicklung und Umwelt- \\ schutz ist ein großer Verdienst des Brundtland-Berichtes. Durch \\ die harmonistische Perspektive des Berichtes wurde aber einer \\ weiten und schwachen Auslegung von Nachhaltigkeit Tür und \\ Tor geöffnet. Von Reinhard Loske
}

mieindustrie bis zu Autobauern und Stromkonzernen praktisch alle für sich, nachhaltig zu wirtschaften - und produzieren weiter giftigste Pestizide, SUV's und Kohlekraftwerke. Dabei hilft ihnen ein Konstrukt, das auch von großen Teilen der Wissenschaft propagiert wird: das Dreieck der Nachhaltigkeit. Durch dieses Dreieck wird suggeriert, es könne - wie bei Tarifverhandlungen - zum Trading zwischen Wirtschaft, Sozial- und Umweltinteressen kommen. In einem solchen Modell haben ökologische Interessen faktisch kaum eine Chance, es sei denn, sie lassen sich in Arbeitsplätzen und neuen Märkten ausdrücken. Wenn es um menschliche Zukunftsinteressen, Interessen der nichtmenschlichen Kreatur oder um unüberwindbare Zielkonflikte geht, zieht die Ökologie hier notwendigerweise den Kürzeren. Das ist kein Modell, um den Klimawandel, den Schwund biologischer Vielfalt oder die Übernutzung und Verschmutzung der Meere zu bekämpfen. Vielmehr öffnet es einer Deutung von schwacher Nachhaltigkeit Tür und Tor, die die Natur für weitgehend ersetzbar hält.

Ich glaube, Nachhaltigkeitsforschung sollte sich vom Dreiecksmodell ab- und dem Leitplanken-Modell zuwenden. Die Naturausstattung ist der Rahmen, in dem sich wirtschaftliche und soziale Entwicklung vollzieht - in Gegenwart und Zukunft. Dabei geht es nicht um einen Primat der Ökologie, sondern um die Anerkennung von physischen Realitäten. Freilich gilt auch: Die Natur ist mehr als nur Grenze. Sie ist vor allem ein Faktor der Mitproduktivität, eine Lieferantin von Dienstleistungen aller Art, ein unverzichtbarer Regenerationsraum.

\section{AUTOR + KONTAKT}

Reinhard Loske, Jahrgang 1959, ist Mitglied des Bundestages und lehrt internationale Politik an der Freien Universität Berlin. Er war Projektleiter der 1996 erschienenen Studie "Zukunftsfähiges Deutschland“ des Wuppertal Instituts, in der erstmals versucht wurde, das Nachhaltigkeitskonzept umfassend auf die Realität eines Industrielandes anzuwenden.

Dr. Reinhard Loske, MdB, Platz der Republik 1, 11011 Berlin. Tel.: 030/2277-1645, E-Mail: reinhard.loske@bundestag.de ch erinnere mich noch gut an die Er-
leichterung, die beim Erscheinen des Brundtland-Berichts 1987 durch das poliEndlich war ein Report erschienen, der nicht von den Grenzen des Wachstums handelte, nicht von der Notwendigkeit eines Abspeckens der Industriestaaten oder

verhärteter Fronten genannt werden. Anders als die großen Vorläuferstudien "Grenzen des Wachstums“ (1972) oder "Global 2000“ (1980) stellte der Brundttastrophale Dimension des industriellen Entwicklungsparadigmas in den MittelIntegration von Wirtschaft, Sozialem und Umwelt. So ließ sich der Skepsis der Entwicklungsländer begegnen, die angesichts Ökologie ablehnten. Und so konnte man in den Industriestaaten auch den Eindruck vermeiden, hier werde zum wiederholten Male eine pessimistische sicherlich zuvörderst die Überwindung der nachhaltigen Entwicklung abe auch offen für feindliche Übernahmen aller Art. Heute reklamieren von der Cheschen Modells der Nachhaltigkeit sind aber beträchtlich. Es ist vage und soll es ja auch sein, um niemanden zu vergrätzen. Deshalb ist das undefinierte Territolicher Titel für den Abschlußbericht der Brundtland-Kommission gewesen.

Wenn man es positiv sehen will, kann metrien zwischen den und innerhalb der Staaten, wurde weitgehend ausgeblendet, bestenfalls angedeutet. „Allen wohl und keinem wehe“, das wäre ein ziemlich ehr(er

Intelligente Umweltpolitik

Die heute populäre Sichtweise, mit grünen Zielen ließen sich schwarze Zahgeneriere Arbeitsplätze, neue Technoloes ohne die starke Versöhnungsthese der Brundtland-Kommission vielleicht gar nicht geben. Das ist und bleibt ihr Verienst.

Die Schattenseiten des harmonistischönigt wurde nichts. Und auch die sonotwendigen Klarheit offen. Aber so deutlich die Analyse auch war, so sehr landeschen Konsens, der niemandem etwas zumutete. Die Antwort blieb eine halbierte: Wachstum, Technologie und zwi-
schenstaatliche Kooperation als Problemlöser. Die weniger angenehme Hälfte, der Umgang mit Naturgrenzen, nicht-nachhaltigen Lebensstilen oder Machtasymsicherlich zuvorderst die Uberwindung Entwicklungsländern legte man in der 
(c) 20I0 Authors; licensee IÖW and oekom verlag. This is an article distributed under the terms of the Creative Commons Attribution Non-Commercial No Derivates License (http://creativecommons.org/licenses/by-nc-nd/3.o/), which permits unrestricted use, distribution, and reproduction in any medium, provided the original work is properly cited. 